\title{
Using Response Surface Methodology of Deep Hole Electrical Discharge Machining Study of Nickel- Base Alloy Inconel-718
}

Shao Hsien Chen ( $\nabla$ e6036@ncut.edu.tw)

National Chin-Yi University of Technology

Kuo-Tai Huang

National Chin-Yi University of Technology

\section{Research Article}

Keywords: Inconel-718, Response Surface Methodology, Deep Hole Electrical Discharge Machining, Tool Wear

Posted Date: May 26th, 2021

DOI: https://doi.org/10.21203/rs.3.rs-203027/v1

License: (c) (i) This work is licensed under a Creative Commons Attribution 4.0 International License.

Read Full License 


\title{
Using Response Surface Methodology of Deep Hole Electrical Discharge Machining Study of Nickel-Base Alloy Inconel-718
}

\author{
Shao-Hsien Chen, ${ }^{1 *}$ and Kuo-Tai Huang ${ }^{2}$ \\ ${ }^{1}$ The Graduate Institute of Precision Manufacturing, National Chin-Yi University of Technology, \\ No.57, Sec. 2, Zhongshan Rd., Taiping Dist., Taichung 41170, Taiwan \\ ${ }^{2}$ Department of Mechanical Engineering, National Chin-Yi University of Technology, \\ No.57, Sec. 2, Zhongshan Rd., Taiping Dist., Taichung 41170, Taiwan \\ * Corresponding author: Email e6036@ncut.edu.tw
}

\begin{abstract}
:
The blades in the high-pressure turbine section of engines of modern aerospace and defense industries need to be drilled for pressurization. The milling and drilling of nickel-base material Inconel-718 are likely to create tool wear and tear, so the drilling process of milling is replaced by deep hole electrical discharge machining (EDM) extensively.
\end{abstract} However, the EDM creates reaming or overcut phenomenon, so reducing overcut by parameter optimization is an important study. This study used will use response surface methodology to establish the influencing factors of machining parameters in the hole enlargement and machining speed. The experimental results show that the main influencing factor in the nickel-base alloy deep hole EDM is the discharge voltage (V), the secondary factor is the discharge current (I). The hole enlargement of processed hole without optimization is $60 \mathrm{um} 100 \mathrm{um}$. The DOE is used for hole enlargement measurement and machining speed measurement to design important parameters, and to predict experiment data analysis. The half normal probability graph, Pareto chart and Analysis of variance (ANOVA) are used to learn about the significant factors of parameters and the influence of interaction. The outlet value of optimized parameters is relatively uniform, and the hole morphology is relatively free of residue stacking. Finally, the inlet and outlet results are improved by $17.9 \%$ compared with the original parameters. The optimization parameter value predicted by the fitted model is $0.0392 \mathrm{~mm}$, and the optimized upper and lower holes validation experiment machining error is $0.0380 \mathrm{~mm}$, and the values are quite close, proving that this prediction model is accurate. The model prediction of this DOE can enhance the applied technology of deep hole EDM for nickel-base alloy.

Keywords : Inconel-718 - Response Surface Methodology 、 Deep Hole Electrical Discharge Machining 、 Tool Wear

\section{Introduction}

The nickel-base high temperature alloy has been used extensively. The nickel-base alloy has good mechanical properties, corrosion resistance, fatigue strength and thermostability at high temperatures, so it can work effectively for long at high temperatures, and it is extensively used in such aerospace parts as turbine blades, combustion chambers, turbine discs, nozzle guides, high-pressure turbine sections, cases and fasteners, as shown in figure 1. However, for long-term existence in the hyperbaric environment of flight, the parts are likely to wear, and the replacement rate is high. The nickel-base superalloy is a material hard to process, the required cutting force is $2 \sim 3$ times of steels. The milling results in very high temperature and stress of tool tip, and the tool flank wear is very severe. To machine the high pressure section of turbine engine, as it is mostly made of high temperature resistant and hardly cut material, and its exterior is mostly geometrical, wherein there are 200 300 cooling holes, as shown in figure 2. If general milling machine is used for drilling process, the cutting tool will wear considerably, so the deep hole discharge is extensively used for machining at present $[1][2][3][4]$. 


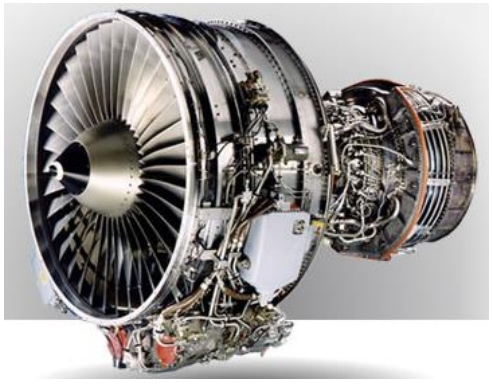

Figure 1 CFM-56 turbine engine [3]

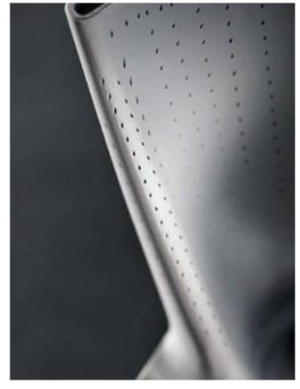

Figure 2 High-pressure turbine section blade EDM [4]
Wright et al. [5] used nickel-base high temperature alloy and general ferrous alloy to study the tool wear property. During the cutting of nickel-base high temperature alloy, at the same speed, the cutting force was twice as high as that of general carbon steel, so the tool tip bore high temperature and high stress. The crater wear was closer to the cutting edge compared with ferrous alloy, the high temperature of tool face resulted in severe tool flank wear, and the tool life was shortened greatly.

Shaw et al. [6] indicated that the cutting of high temperature alloy, e.g. Waspaloy with strong strain hardenability, had groove wear, which often occurred in tool flank cutting depth, forming groove deep wear which extended to the tool face, leading to tool tip breakage during tool cutting. Because the high plastic deformation of cutting edge creates high strain hardening, leading to local high temperature. The higher the material strain hardening is, the more severe is this trend.

Konig et al. [7] used laser heating for hard-to-cut material in the experimental process, and proved this processing mode could reduce tool wear and tear, reduce the processing cost and increase the productivity of processing.

Soni and Chakraverti [8] used 3mm copper-tungsten electrode to study the discharge drilling characteristic of machining depth $10 \mathrm{~mm}$ of Ti alloy. The paper discussed the influence of two factors, including discharge current and electrode speed, on such processing characteristics as material removal rate and electrode consumption rate. The data were used for statistical analysis by experimental plan and the mathematical model was built, and the machining differences among different electrode motion modes were worked out.

Yan et al. [9] conditioned copper electrodes in different diameters to study microhole EDM of carbide. The paper indicated that the microhole precision and electrode consumption rate after machining were influenced mainly by the polarity, electrode geometry and speed, and when the electrode rotation speed was moderately increased and the electrode geometry had appropriate unilateral notch, the dielectric fluid disturbance was assisted effectively and the removal of machining chips was promoted, the opportunity of secondary discharge of hole wall was reduced, so as to maintain the hole precision after machining.

Huang [10] studied the influence of machining parameters on such processing characteristics as electrode corner consumption and electrode length consumption when the working area was smaller than $50 \mathrm{~m} \mathrm{~m}^{2}$ and the machining depth was fixed at $3 \mathrm{~mm}$. Based on statistical analysis of ignition delay time, when the number of discharge waves of ignition delay time equal to zero increases, the electrode corner consumption will increase and the material removal rate will decrease, and the working area and the peak current are the major factors influencing the number of this kind of discharge waves.

Peng [11] used $2 \mathrm{~mm}$ red brass and yellow brass electrode materials to study the discharge drilling of machining depth $12.5 \mathrm{~mm}$ for SKD11, K10 and conducting ceramic. The paper discussed the processing characteristics of the three materials in material removal rate, electrode consumption rate and surface roughness under different discharge energy supply forms, electrode materials and slipstream pressures, so as to provide the reference for selection and setting of parameters for the processing of various materials.

Yeh [12] used $3 \mathrm{~mm}$ brass pipe electrode to study discharge perforation of SKD11, discussed the effect of discharge current, capacitance and spindle feedrate parameters on machining, and used aqueous graphite powder solution as dielectric fluid. The paper indicated that when the graphite concentration in the dielectric fluid increased, the carbon layer adhered to the part between two poles in the machining process and the discharge was dispersed, the material removal rate, electrode consumption rate and inlet-outlet diameter difference decreased, and the surface roughness got better. 
Cheng [13] proposed a second-order fuzzy logic control method. In Stage 1, the discharge conditions of regular sampling points were established and classified, and the quantity of discharge conditions in the computation period was unified to obtain the discharge condition of each computation period. The second-order fuzzy theory used the periodic discharge condition of previous order as input to deduce the servo feed strategy. The double closed-loop control system for deep hole discharge was designed based on this method. The deep microhole in diameter of $0.1 \sim 0.5 \mathrm{~mm}$ with depth-diameter ratio larger than 10 could be obtained stably by designing the discharge system, and the optimization experiment was proved to be a very effective method for increasing the efficiency of EDM.

$\mathrm{Su}[14]$ indicated in the deep hole EDM process, the material removal rate, electrode consumption rate and the ability to complete through hole were influenced as the machining depth changed. The experimental result showed that the material removal rate did not decrease as the machining depth increased, it showed a steady state. The electrode consumption rate was not influenced by machining depth, it remained in a steady state. The ability to complete through hole declined as the machining depth increased. Therefore, the paper proposed an immersion processing method, which could solve the machining problem that the through hole could not be completed smoothly, and could improve the outlet end surface condition after machining. Finally, the information of small diameter deep hole straightness was obtained by using short circuit detection mode. The measurement result showed that the axis wobble increased with the machining depth, and the smaller the electrode diameter was, the larger was the wobble.

\section{Discharge Principle and Overcut}

\section{Phenomenon}

\section{2-1 EDM principle}

According to the discharge waveform measurability of power system, general deep hole EDM is divided into voltage and current waveforms, as shown in Figure 2-4, the design is divided into iso-energy EDM and iso-frequency EDM.

1. Iso-frequency discharge: each discharge cycle has equal cycle, meaning the arc strike time (Td) discharge period
(ON TIME) and discharge off time (Pulse Off-Time) are fixed, i.e. iso-frequency discharge. However, the defect in this power supply is that the discharge period is unfixed, so the discharge energy is different every time, the craters have different sizes and depths after discharge, the machining speed is unstable, and the surface roughness is poor. For the discharge pulse with equal period, the circuit design of waveform generator is relatively simple. Figure 3 shows the schematic diagram of iso-frequency discharge voltage and current waveforms [21][22].

2. Iso-energy discharge: the discharge period of Iso-pulse or Iso energy is a fixed cycle, the discharge cycle is a fixed time, so the discharge energy is fixed. As the discharge period length of iso-energy discharge is fixed, the discharge energy of each pulse is fixed, the craters after discharge have similar sizes, so the machined surface has better roughness. The iso-energy EDM is mostly used in current EDM industry. Figure 2-6 shows the schematic diagram of iso-energy discharge voltage and current waveforms [23] [24][25].

The EDM process is a natural physical phenomenon, it is unlikely to observe the overall discharge process and make detailed analyses. Therefore, the values and fitness of various conditions must be observed in the waveform of oscillograph, as shown in Figure 4. The operator-determined discharge condition becomes the unique method to control machining results. These controllable discharge conditions are the machining parameters. General EDM parameters include on time, off time, LA, LV, CF, GAP, SER, SS, WL and so on [15][16].

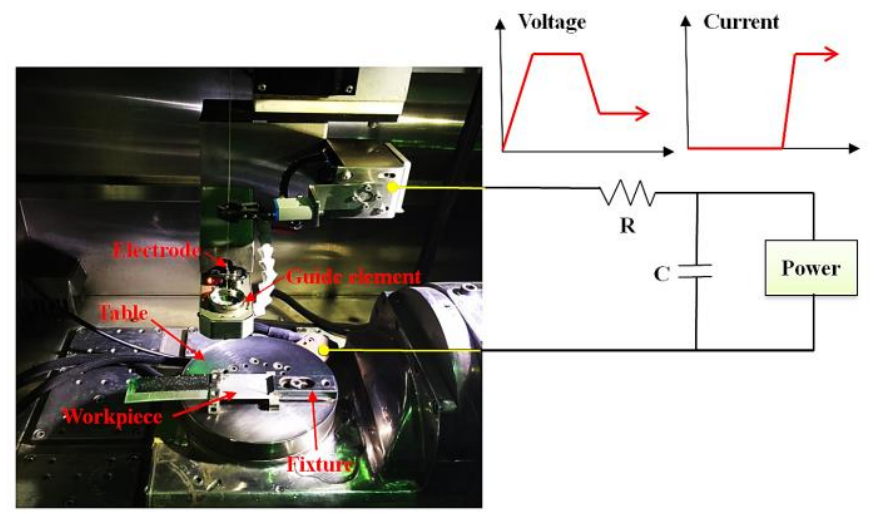

Figure 3 Iso-frequency discharge voltage and current waveforms 


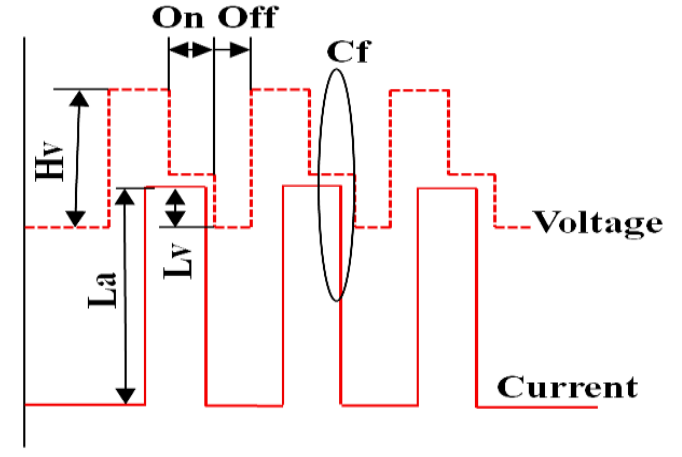

Figure 4 operator-determined discharge conditions

\section{2-2 Hole enlargement and electrode consumption}

Hole enlargement: the enlargement and straightness of hole in deep hole machining are important reference indicators, the length of machining time and the times of secondary discharge can influence the difference between inlet aperture and outlet aperture. According to the equation derived from the study of EDM surface characteristics, the hole enlargement is equal to electrode outer diameter - drill size [26]. The eight parameters in this experiment can influence the difference between inlet and outlet apertures, the unit is $\mu \mathrm{m}$. The workpiece surface condition after machining is preliminarily observed through optical microscope and the difference between inlet aperture and outlet aperture is measured in this experiment. The brass tube is used as electrode in this experiment, the difference between the weights before and after machining ( $\mathrm{mg}$ ) is measured and divided by machining time ( $\mathrm{min}$ ) to obtain the electrode consumption $(\mathrm{mg} / \mathrm{min})$, the electrode consumption rate is divided by material removal rate and multiplied by 100 to obtain relative electrode consumption rate [17].

Empirical equation of hole enlargement:

$$
\mathrm{HE}=0.0045(\mathrm{Ip} 0.7 \times \mathrm{Ton} 0.3)
$$

Electrode wear the common wear conditions which create errors in general EDM process are divided into front wear and flank wear, as shown in figure 5.

\section{(1) Front wear}

In the deep hole discharge process, as the workpiece and electrode have material removal, the electrode length is shortened as the front end of electrode is worn, leading to insufficient machining depth, as well as errors in the depth of the machined workpiece.

\section{(2) Flank wear}

Due to electrode flank wear, the tip is worn into a taper, as shown in Figure 2-13, this condition will create errors in workpiece dimensions, it must be handled when the wear reaches a certain level, or the electrode must be changed.

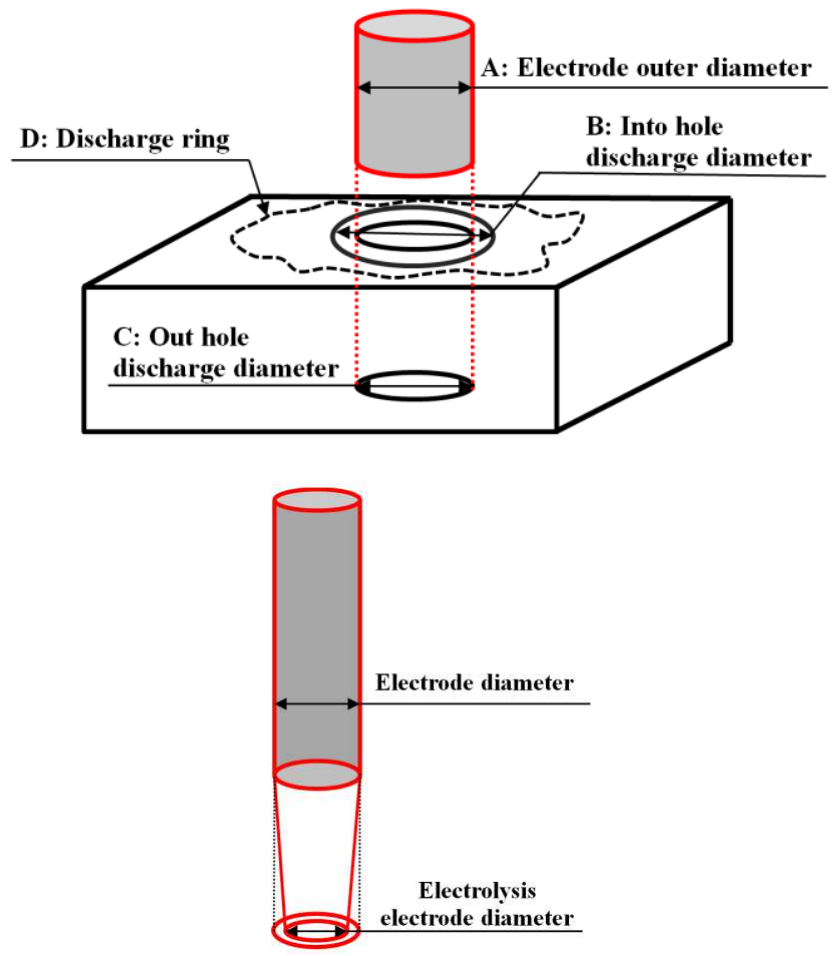

Figure 5 Schematic diagram of electrode wear and workpiece

\section{2-3 Response surface methodology}

The response surface methodology (RSM) is a method assisted by statistical method to compute the relation between multiple independent variables in unknown function and a response variable, it is combined with DOE and regression analysis [18]. The required response value and the corresponding input parameter position are obtained in the preset input parameter space by DOE. Generally, the RSM is represented graphically, aiming to provide a set of effective analysis and solution for product design optimization, process optimization and system optimization problems in the process. The application has the following two constraints: (1) applicable to continuous system, assuming that the measurement graduation of all response values and independent variables is continuous; (2) the independent variables influencing the system are measurement (controllable and uncontrollable variables). Under the assumption of RSM and the constraints of application system, 
the optimal experimental values or activity variable values can be obtained effectively [19].

In experimental analysis of RSM, if the input parameters influencing the response value $\mathrm{y}$ are $\mathrm{x}_{1}, \mathrm{x}_{2, . .}, \mathrm{x}_{\mathrm{p}}$, and $\mathrm{x}$ is the independent variable, the unknown function (dependent variable) is

$y=f\left(x_{1}, x_{2}, . ., x_{p}\right)+\varepsilon$

where $\varepsilon$ is the error (or experimental error) of the response variable $\mathrm{y}$, if $E(y)=f\left(x_{1}, x_{2}, . ., x_{p}\right)=\eta$ denotes the response of the expected value, then:

$\eta=f\left(x_{1}, x_{2}, . ., x_{p}\right)$

The surface represented by $\mathrm{f}$ is known as Response Surface. The generally discussed response surface is a surface with only one Global Maximum or Minimum. As shown in Figure 6, the left figure shows a surface with one maximum value, and the right figure shows a surface with only one minimum value.

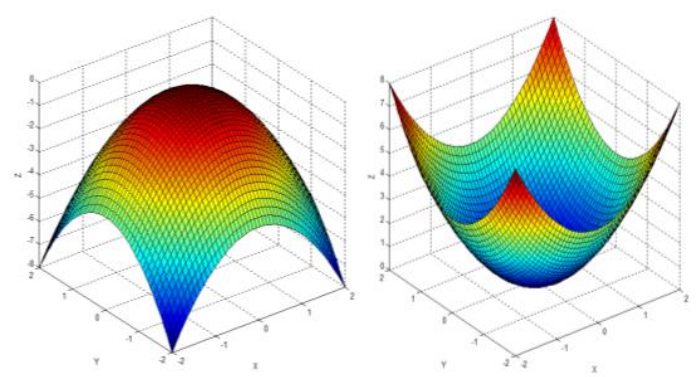

Figure 6 Maximum and minimum surfaces of response surface [20]

If the response can be imitated by the linear function of an independent variable, the approximate function is called First-Order Model, the model can be expressed as

$$
y=\beta_{0}+\beta_{1} x_{1}+\beta_{2} x_{2}+\ldots+\beta_{p} x_{p}+\varepsilon
$$

If the system has curvature, higher-order polynomial is required, e.g. Second-Order Model, the mathematical expression of the approximate function of this second-order model is expressed as follows:

$$
y=\beta_{0}+\sum_{i=1}^{p} \beta_{i} x_{i}+\sum_{i=1}^{p} \beta_{i i} x_{i}^{2}+\sum_{i<j} \sum \beta_{i j} x_{i} x_{j}+\varepsilon \quad 3-4
$$

The RSM is a sequential procedure. When the response surface is far from the optimal condition point, as shown in Figure 3-3, there is a little curvature in the system, the first-order model is optimal at this point, the purpose is to move somewhere about the approximate value of optimal value as soon as possible, the Method of Steepest Ascent is used, which increases the movement procedure along the maximum response variable, once it reaches somewhere about optimal point, the second-order model is used for analysis to find out the optimal point, the Central Composite Design (CCD) is used in general. The CCD is a two-level full or fractional factorial design, augmented by a few processes, so that the estimation of the second-order response surface model is possible.

\section{Experimental plan and process}

According to the deep hole machining influencing factor graph, there are seven main classes of factors which influence the deep hole machining accuracy: (1) control system (2) discharge system (3) electrode system (4) setup environment (5) mechanism system (6) working fluid (7) workpiece. The controllable parameter in the machining process is discharge system. The factor parameters influencing the precision machining in the discharge system includes (1) ON TIME, (2) OFF TIME, (3) current (I), (4) voltage (V) (5) capacitance (CF), (6) feedrate (GAP), (7) voltage across poles (SER), (8) spindle speed (SS), the effects on electrode consumption rate and material removal rate are measured and tested. The parameters. This study will use deep hole EDM for experiment. The machine specifications are shown in table 1 and figure 7 , so as to confirm the influence of the consumption of working electrode in this test on the measured data to attain the goal of this study. The overall flow of this experiment is shown in Figure 8.

Table 1 Experiment adjustment parameters to be controlled

\begin{tabular}{|c|c|}
\hline ITEM & AD5L \\
\hline Max. job load size $(\mathrm{X} / \mathrm{Y} / \mathrm{Z} \mathrm{mm})$ & $800 \times 400 \times 250$ \\
\hline Max. job load weight $(\mathrm{kgw})$ & 180 \\
\hline X,Y axis travel $(\mathrm{mm})$ & $350 \times 250$ \\
\hline Z1 axis ram travel (mm) & 250 \\
\hline Z2axis travel (mm) & 400 \\
\hline Automatic tool and guide change \\
(mm)
\end{tabular}




\begin{tabular}{|c|c|}
\hline Max. electrode length $(\mathrm{mm})$ & 400 \\
\hline $\begin{array}{c}\text { Distance form guide to table } \\
(\mathrm{mm})\end{array}$ & $30-230$ \\
\hline
\end{tabular}
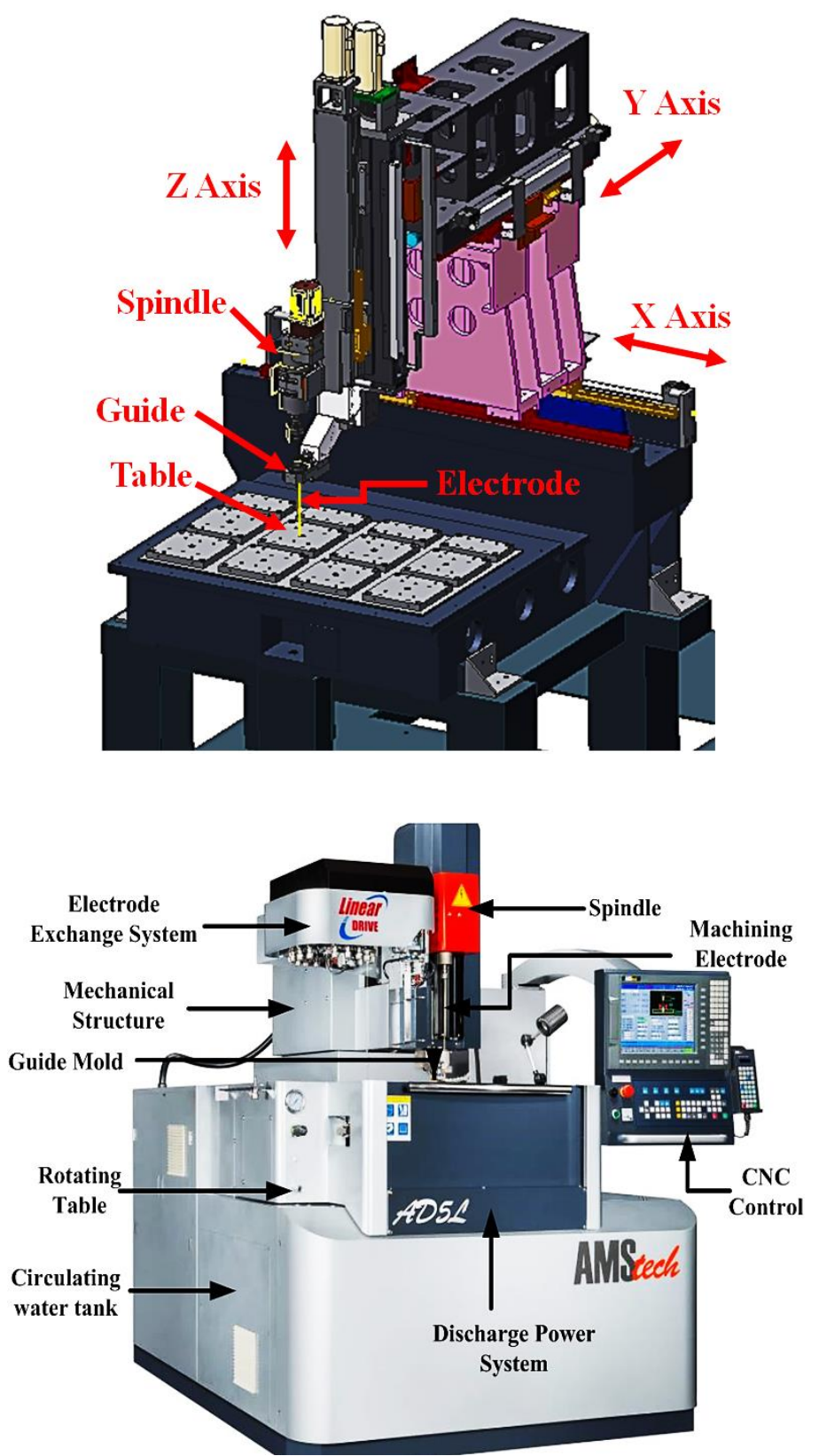

Figure 7 Schematic diagram of mechanical structure and control system [26]

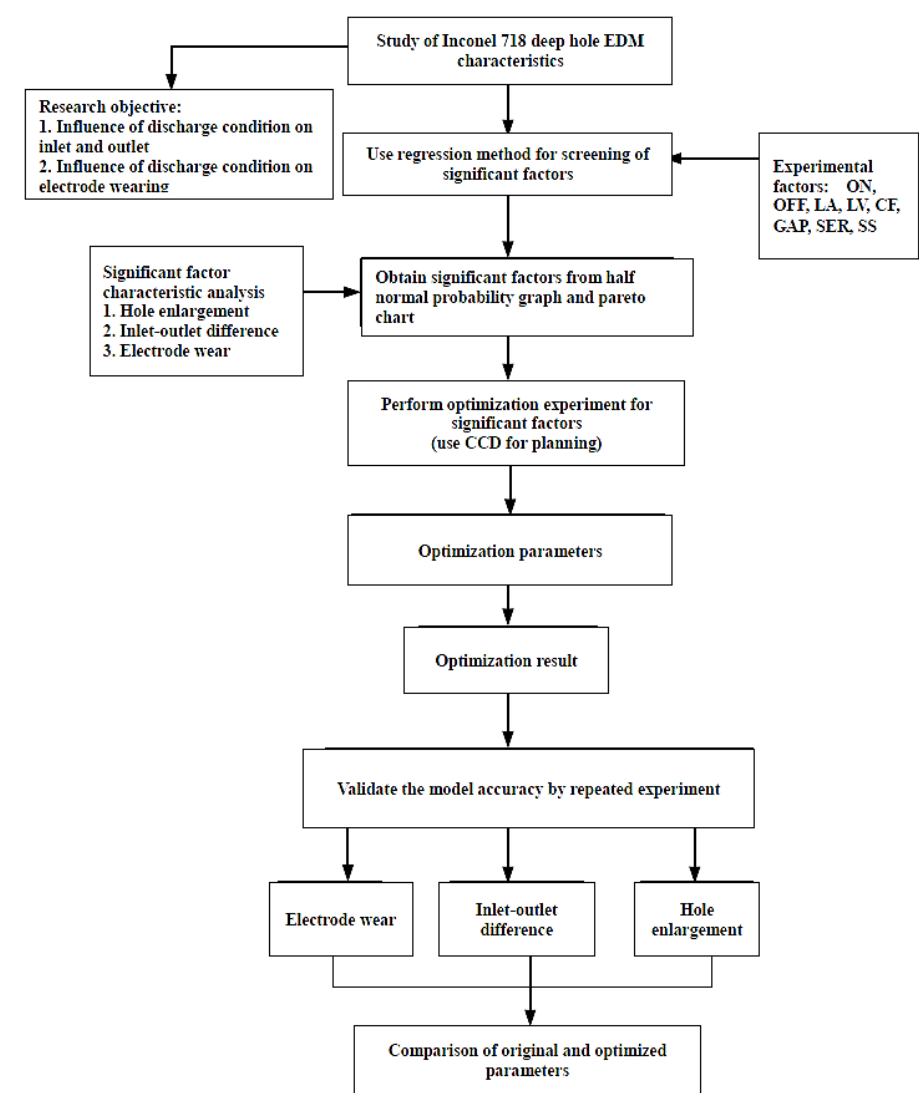

Figure 8 Experimental test and processing flow chart

\section{Results and Discussion}

The deep hole EDM is used for discharge drilling of Inconel 718 nickel-base alloy sample in the experiment of this study. Afterwards, the image measuring instrument is used as measurement instrument to measure the aperture sizes of discharge drilling inlet end and outlet end respectively. The experiment data measurement results are further analyzed and integrated, and the DOE is used to discuss the correlation between deep hole discharge in electrode tube diameter of $0.6 \mathrm{~mm}$ and Inconel 718 material machining parameter adjustment and the combination of optimum parameters, so as to obtain the optimal machining effect. The discussion process can be divided into two stages. Stage 1 is the screening experiment, analyzing the significance of experimental factors to find out the significance, so as to know the number of experiments and the required resolution for experimental analysis. The influence of hole enlargement and electrode wear is found out according to experimental results, and the parameters are analyzed. Stage 2 is also known as optimization experiment, the regression equation is obtained 
by using Central Composite Design from the screening experiment result, so as to obtain the optimal values.

\section{4-1 Deep hole discharge parameters screening experiment}

This study uses eight factors and two levels to plan the discharge drilling process conditions, the electrode is brass tube 0.6 caliber, and the recommended values of machining conditions are listed in table 2, the deep hole EDM of Ching-Hung Machinery \& Electric is used for drilling. All the experiments are divided into two stages. In Stage 1, the Fractional Factorial Design is used to design 128 groups of experimental machining conditions, the subject of measurement is the size of enlargement, the selected EDM conditions include discharge time (on time), off time, number of current stages (I), voltage (V), capacitance (CF), GAP (feedrate), SER (servo voltage) and spindle speed. In the combination of experimental plan, as the eight-factor two-level experimental plan is used, if the Full Factorial Experiment is used, there will be lots of experiments, so the fractional factorial experiment proposed by Box and Hunter et al. is used to generate 128 experimental combinations as criteria of screening, based on the results of deep hole discharge machining, and the ANOVA shows whether various experimental factors have specific significance.

Table 2 The original manufacturer's recommended values of machining conditions [26]

\begin{tabular}{|c|c|c|c|c|c|c|c|c|}
\hline Caliber/mm & ON & OFF & I & V & CF & GAP & SER & SP \\
\hline 0.6 & 16 & 14 & 12 & 42 & 0 & 7 & 10 & 0 \\
\hline
\end{tabular}

Table 3 Experimental factor table

\begin{tabular}{|c|c|c|c|c|c|c|c|c|}
\hline & ON & OFF & I & V & CF & GAP & SER & SP \\
\hline $\begin{array}{c}\text { Low } \\
\text { level }\end{array}$ & 5 & 28 & 7 & 42 & 0 & 6 & 9 & 40 \\
\hline $\begin{array}{l}\text { High } \\
\text { level }\end{array}$ & 20 & 100 & 17 & 60 & 4 & 8 & 11 & 0 \\
\hline
\end{tabular}

In the discussion about deep hole EDM efficiency, there are very large differences in the hole enlargement under different parameter conditions. According to the screening experiment in table 3 , the maximum hole enlargement is $0.176 \mathrm{~mm}$, and the minimum is $0.015 \mathrm{~mm}$. It is obvious that different combinations have different hole enlargements and inlet and outlet changes under different energy conditions. In the significance screening experiment on deep hole EDM, the measured hole enlargement is used for ANOVA. The significant main effect or interaction, i.e. significant influencing factor, can be observed in the half normal probability graph. Among the eight machining parameters, the OFF-Time, current $\mathrm{I}$, voltage $\mathrm{V}$ and capacitance $\mathrm{CF}$ are significant factors, so the related parameters are used for first-order analysis.

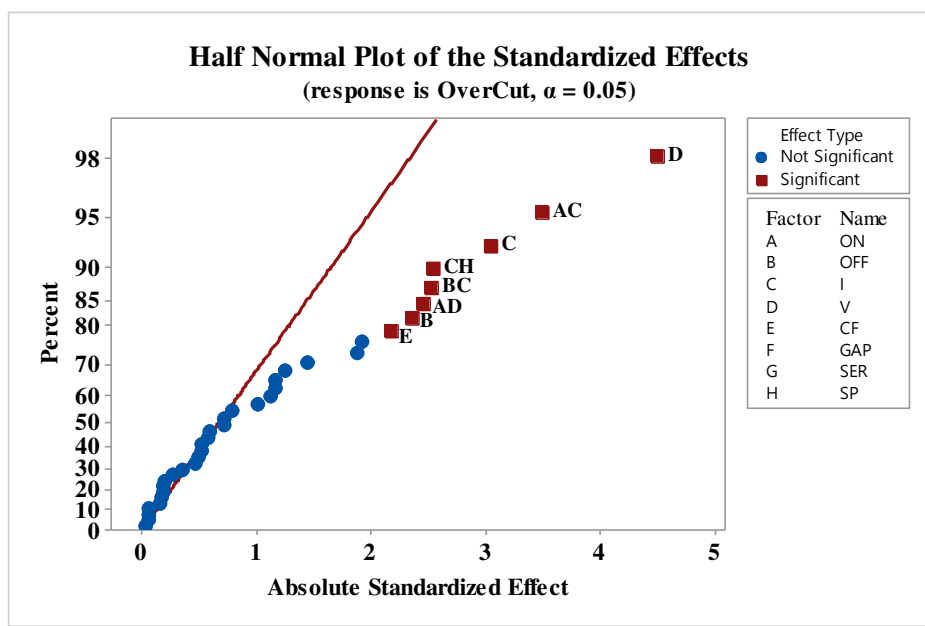

Figure 9 Half normal probability graph considering interaction under second order

In the first-order half normal probability and pareto chart analysis, the significant factors can be used in optimization experiment, as shown in figures 9 11. There is a normal line at 1.980 in the pareto chart, meaning $\mathrm{P}$ value $=0.05$ is reference, when $\mathrm{P}$ value $>0.05$, meaning the experimental factor is insignificant, $\mathrm{P}$ value $<0.05$ represents significant factor. It is observed that the OFF-Time, current I, voltage V and capacitance $\mathrm{CF}$ are significant factors, their contributions to influence are shown in figure 12.




Figure 10 Half normal probability graph considering first order

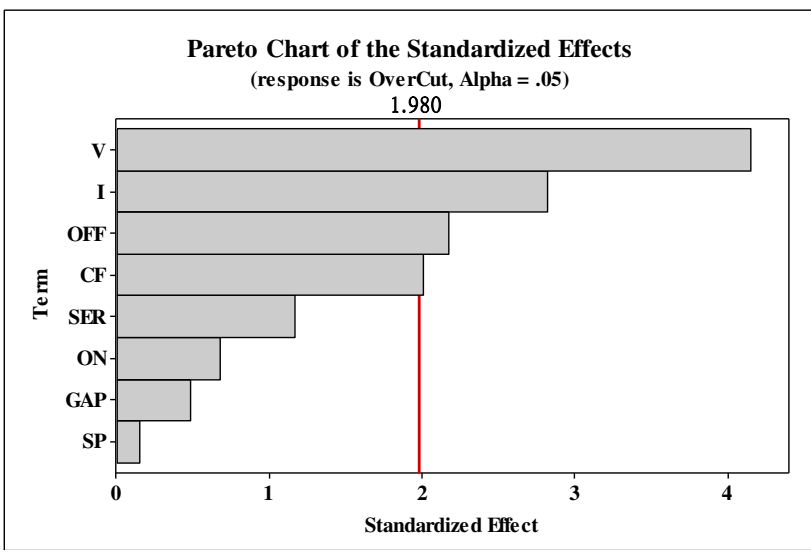

Figure 11 Pareto chart considering first order

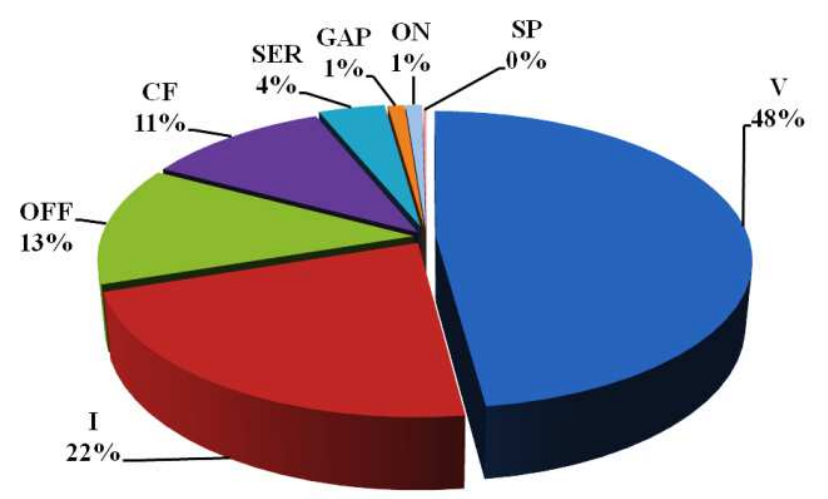

Figure 12 Distribution diagram of factor contribution to hole enlargement

\section{4-2 Analysis of influential parameters according to inlet-outlet difference and electrode wear}

According to the aforesaid inlet and outlet screening experiment, the OFF-Time, current $\mathrm{I}$, voltage $\mathrm{V}$ and capacitance $\mathrm{CF}$ are significant factors. When the machining time is short, the material removal rate is relatively high, and the required energy is higher, so the electrode consumption is increased, the parameters of significant factors will be discussed. When the off time is changed, the experimental result is shown in Figure 13, there is slight difference in hole enlargement and inlet and outlet error value (difference value is about within $0.01 \mathrm{~mm}$ ), so the off time has less effect on hole enlargement and outlet. When the off time is before 70us, the electrode consumption will increase with off time. When the off time is 84us, as the off time is too long, the energy decreases, so that the electrode consumption decreases. When the current of machining parameters is changed, the experimental result is shown in Figure 14, the discharge is effective until the energy is $\mathrm{I}=12 \mathrm{~A}$, under different current conditions, the hole enlargement and inlet and outlet error value are changed obviously. In low current region, the generated energy is lower and unstable, so the electrode size consumption is large. When the current exceeds $\mathrm{I}=14.5 \mathrm{~A}$, the electrode size consumption is smaller, but the workpiece error is markedly increased, the first cause is the increase in discharge energy.

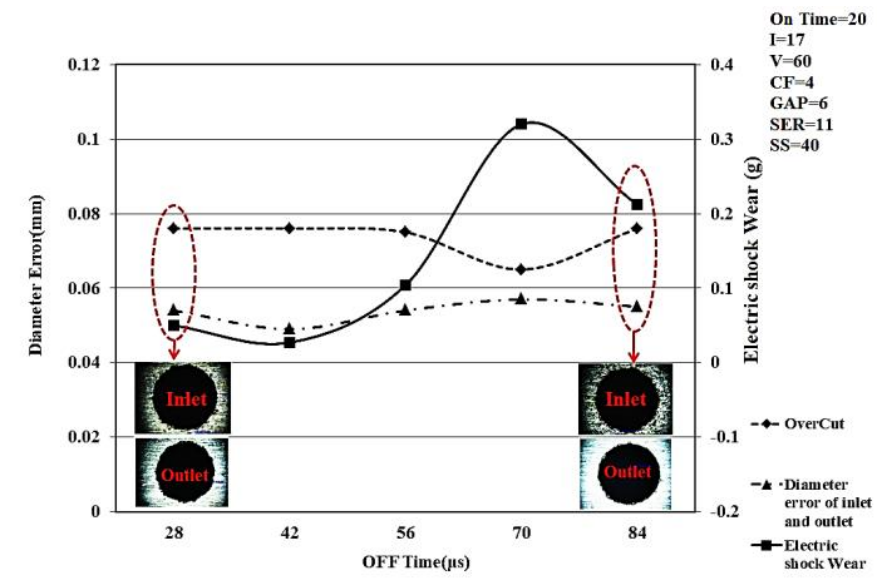

Figure 13 Off time influencing parameter analysis

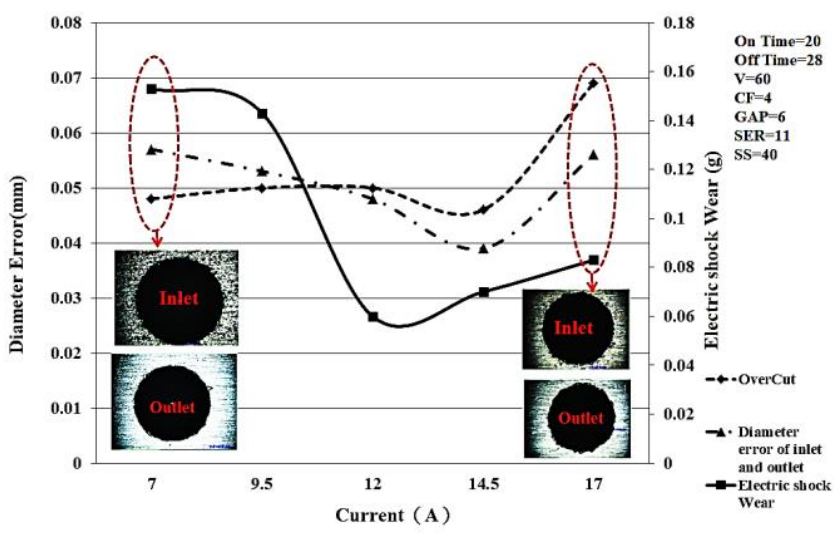

Figure 14 Current influencing parameter analysis

When the voltage of machining parameters is changed, the experimental result is shown in Figure 15, before discharge voltage $55 \mathrm{~V}$, the electrode consumption is relatively stable (difference is about $0.01 \mathrm{~g}$ ), there will be positive effect on the consumption in this region. When the voltage is $60 \mathrm{~V}$, the energy increases, and the consumption, hole enlargement and inlet and outlet error increase accordingly. When the capacitance of machining parameters is changed, the experimental result is shown in Figure 16. Under different capacitance conditions, it is observed that the trend of hole 
enlargement and inlet and outlet error is similar to voltage state, because higher capacitance will generate higher instantaneous voltage. The electrode wear shows that the capacitance has greater effect, it is observed when the capacitance $\mathrm{CF}=2$, the electrode consumption is lower (difference is about $0.2 \mathrm{~g}$ ).

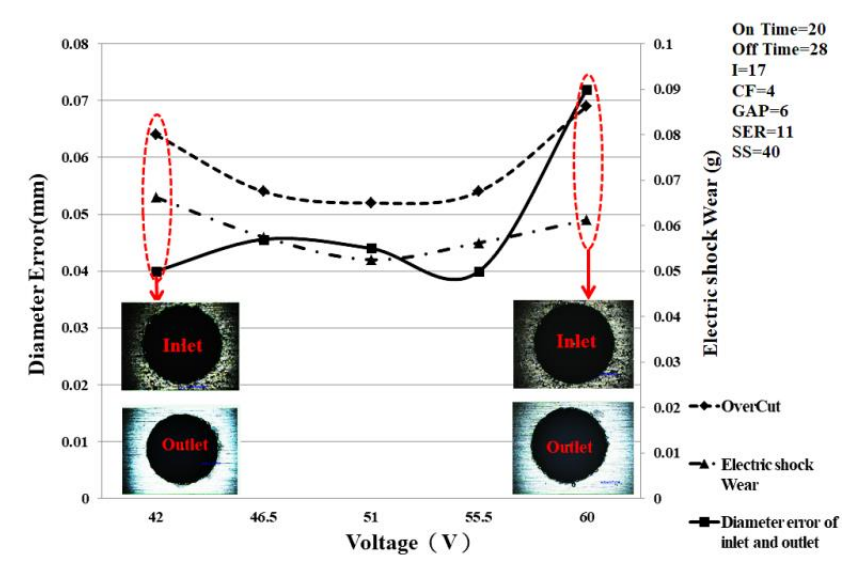

Figure 15 Voltage influencing parameter analysis

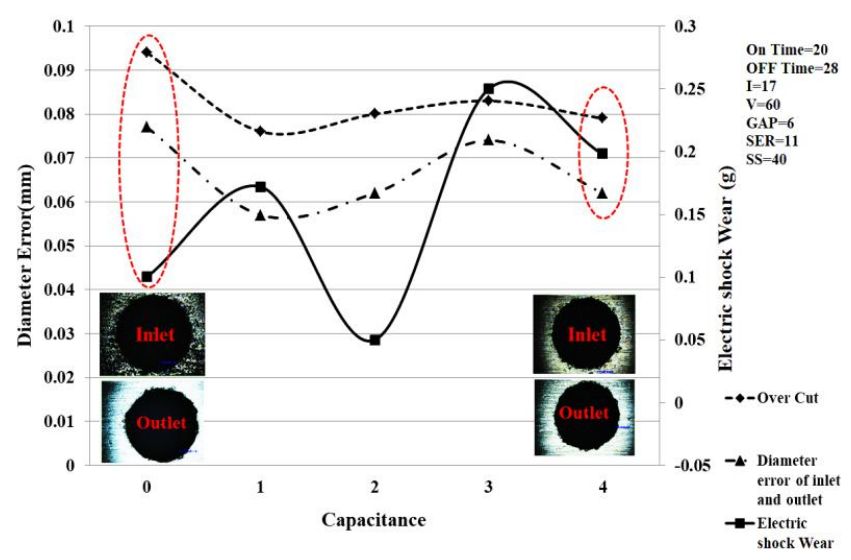

Figure 16 Capacitance influencing parameter analysis

\section{4-3 Optimization experiment on deep hole discharge parameters}

The off time, machining current, voltage and capacitance are significant factors in experimental screening process, so the optimization experiment on significant factors is analyzed, the parametric programming increases center point and axial point in full factorial experiment design method, the significant factors (off time, machining current, voltage, capacitance) are classified as key parameters in optimization experiment in the measurement of upper and lower holes, the center point and axial point factors and levels are shown in Table 4.

Table 4 Factor and level table with center point and axial point

\begin{tabular}{|l|l|l|l|l|l|}
\hline & -2 & -1 & 0 & 1 & 2 \\
\hline $\mathrm{V}$ & 42 & 46.5 & 51 & 55.5 & 60 \\
\hline $\mathrm{I}$ & 7 & 9.5 & 12 & 14.5 & 17 \\
\hline
\end{tabular}

\begin{tabular}{|l|l|l|l|l|l|}
\hline OFF & 28 & 46 & 64 & 82 & 100 \\
\hline CF & 0 & 1 & 2 & 3 & 4 \\
\hline
\end{tabular}

In the first-order factor level combination, the first-order regression equation model is

$\mathrm{y}=\alpha_{0}+\alpha_{1} V+\alpha_{2} I+\alpha_{3} O F F+\alpha_{4} C F$

First-order model Lack-of-Fit analysis

$\mathrm{H}_{0}: \mathrm{y}=\alpha_{0}+\alpha_{1} V+\alpha_{2} I+\alpha_{3} O F F+\alpha_{4} C F$
$\mathrm{H}_{0}: \mathrm{y} \neq \alpha_{0}+\alpha_{1} V+\alpha_{2} I+\alpha_{3} O F F+\alpha_{4} C F$

When the regression equation analysis is confirmed by Lack-of-Fit test and residual test, the Lack-of-Fit is $\mathrm{DF}=20$, the pure error is $\mathrm{DF}=3$, wherein the $\mathrm{P}$ value in Lack-of-Fit test is 0.46 , which is larger than 0.05 , not rejecting null hypothesis, $\mathrm{F}<\mathrm{F}_{(0.05,20,3)}$ so not rejecting null hypothesis. The calibration coefficient $\mathrm{R}^{2}=0.8101$ judgment result is too low, meaning the first-order model is not suitable, there may be second-order model, so the axial point is used for second-order ANOVA.

$$
F=\frac{0.000056}{0.000041}=1.365<F_{(0.05,20,3)}=8.66019
$$

The second-order regression model and Lack-of-Fit test are fitted for model accuracy, the second-order regression model is expressed as follows.

$$
\begin{aligned}
\mathrm{y}=\alpha_{0}+\alpha_{1} V+ & \alpha_{2} I+\alpha_{3} O F F+\alpha_{4} C F+\alpha_{5} V I+\alpha_{6} V O F F \\
& +\alpha_{7} V C F+\alpha_{8} I O F F+\alpha_{9} I C F \\
& +\alpha_{10} O F F C F+\alpha_{11} V^{2}+\alpha_{12} I^{2}+\alpha_{13} O F F^{2} \\
& +\alpha_{14} C F^{2}
\end{aligned}
$$

According to analysis, the Lack-of-Fit is $\mathrm{DF}=10$, the Pure Error is DF=3, wherein the $\mathrm{P}$ value in Lack-of-Fit test is 0.432 , larger than $0.05, \mathrm{~F}<\mathrm{F}_{(0.05,10,3)}$ according to $\mathrm{F}$-test, so null hypothesis is not rejected. The calibration coefficient $\mathrm{R}^{2}=0.8918$ judgment result is higher than first-order model. The $\mathrm{P}$ coefficient is observed in analysis, the quadratic term and interaction term coefficients are insignificant, meaning the two factors have slighter effect on system, so that the less influential parameters are deleted and the ANOVA is performed after adjustment.

$\mathrm{F}=\frac{0.000058}{0.000041}=1.414<F_{(0.05,10,3)}=8.785525$

Second-order regression model and Lack-of-Fit test after fit adjustment:

$y=\alpha_{0}+\alpha_{1} V+\alpha_{2} I+\alpha_{3} C F$ 
$H_{0}: y=\alpha_{0}+\alpha_{1} V+\alpha_{2} I+\alpha_{3} C F$

$H_{1}: y \neq \alpha_{0}+\alpha_{1} V+\alpha_{2} I+\alpha_{3} C F$

According to the Lack-of-Fit test of second-order model, the Lack-of-Fit of this model is $\mathrm{DF}=19$, the Pure Error is $\mathrm{DF}=5$, and the $\mathrm{P}$ value of Lack-of-Fit is $0.25>0.05$, there is no significant Lack-of-Fit, the calibration coefficient $R^{2}=0.8067$, so according to F-test,

$F=\frac{0.000059}{0.000031}=1.903<F_{(0.05,19,5)}=4.56782$

Table 5 Regression coefficient values after adjustment

\begin{tabular}{|l|l|l|}
\hline Term & Coef & P \\
\hline Constant & 0.074633 & 0.000 \\
\hline V & -0.008625 & 0.000 \\
\hline I & -0.005708 & 0.001 \\
\hline CF & -0.003375 & 0.032 \\
\hline R-Sq $=80.67 \%$ & \multicolumn{2}{|l|}{} \\
\hline
\end{tabular}

So the regression prediction equation can be solved as follows.

$\mathrm{y}=0.074633-0.008625 \mathrm{~V}-0.005708 I-0.003375 C F$

According to the optimization result in figure 17, the parameters of optimized conditional forecast are voltage (V) $60 \mathrm{~V}$, current (I) 17A, capacitance $(\mathrm{CF}) 4$, the prediction value of upper-lower hole error amount is $0.0392 \mathrm{~mm}$.

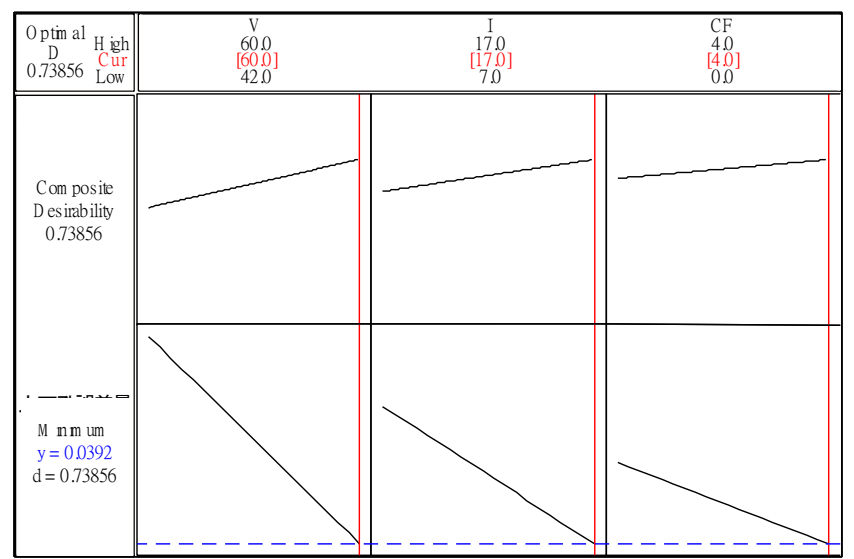

Figure 17 Experimental parameter optimization and prediction result

\section{4-4 Actual machining validation}

The original parameters and optimized parameters are used to process 10 holes continuously in the validation experiment, the original parameters are the company recommended parameters, the average errors of 10 holes are shown in figure 18. The hole morphology, hole edge morphology and carbon residue level are observed after discharge in the experiment on the original parameters, the outlet observation shows the discharge ring is larger, the crater phenomenon (residue stacking) is relatively apparent, the numerical error of outlet is larger and unstable.

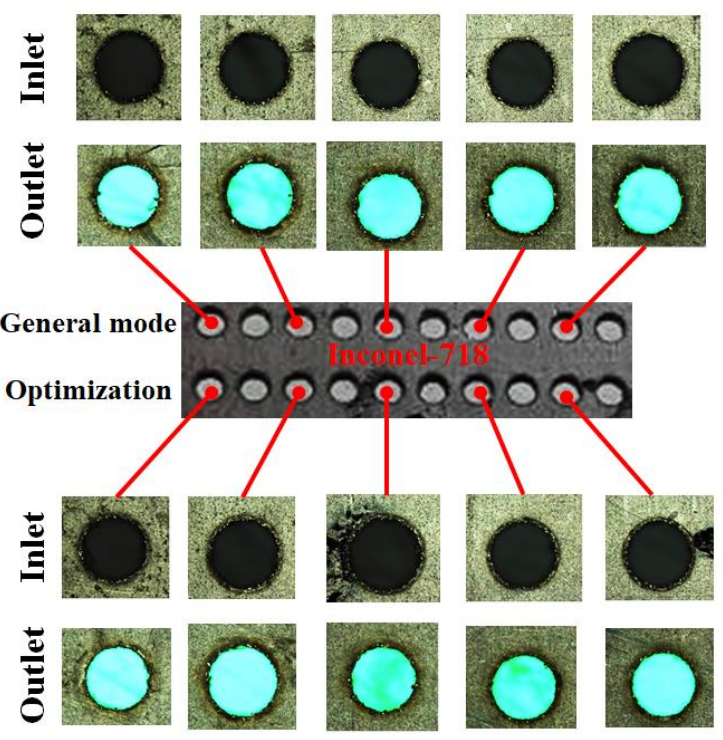

Figure 18 Finished nickel-base alloy sampling 10 hole processing

The hole morphology, hole edge morphology and carbon residue level are observed after discharge in the optimized parameter robustness experiment. The outlet observation shows the discharge ring is not large, and the crater phenomenon (residue stacking) is not obvious, the numerical error of outlet is smaller, the outlet stability is better. The upper-lower hole error predicted by regression experiment model is $0.0392 \mathrm{~mm}$, after continuous 10 hole processing of optimization experiment and the average is taken, the actual upper-lower hole error is optimized to $0.380 \mathrm{~mm}$, close to prediction value, proving that the prediction reliability of the fitted model of this experiment is about $80 \%$, but the reliability validated by actual machining is close to the predicted value, and according to the robust experiment, the inlet and outlet difference of optimized parameters is improved by $17.9 \%$ compared with the original parameters, so this experimental model is correct.

Table 6 Parameter matching result

\begin{tabular}{|c|c|c|c|c|c|c|c|c|c|c|c|c|}
\hline & ON & OFF & I & $\mathrm{V}$ & $\mathrm{CF}$ & GAP & SER & SP & $\begin{array}{c}\text { Mean } \\
\text { diameter } \\
\text { of upper } \\
\text { hole } \mathrm{mm} \\
\end{array}$ & $\begin{array}{c}\text { Mean } \\
\text { diameter of } \\
\text { lower hole } \\
\text { mm }\end{array}$ & $\begin{array}{c}\text { Error } \\
\mathrm{mm}\end{array}$ & $\begin{array}{c}\text { Improve } \\
\text { ment }\end{array}$ \\
\hline $\begin{array}{l}\text { Original } \\
\text { parameter }\end{array}$ & 16 & 14 & 26 & 42 & 0 & 7 & 10 & 40 & 0.6769 & 0.6210 & 0.0559 & 0.0219 \\
\hline $\begin{array}{l}\text { Optimized } \\
\text { parameter }\end{array}$ & 16 & 14 & 17 & 60 & 4 & 7 & 10 & 40 & 0.6682 & 0.6302 & 0.0380 & $17.9 \%$ \\
\hline
\end{tabular}




\section{Conclusion}

This study built a prediction model for electrode wear and upper-lower hole error, the principle is DOE. The optimization and parameter validation of significance of hole enlargement, electrode wear and upper-lower hole error are concluded below.

(1) In different conditions of off time, the difference in hole enlargement and inlet and outlet error value is slight (difference value is about within $0.01 \mathrm{~mm}$ ), so the off time has less influence on hole enlargement and outlet factors. Before 70 us of off time, the electrode consumption increases with off time. When the off time is 84 us, the off time is too long, the energy decreases, so that the electrode consumption decreases.

(2) In different current conditions, the difference in hole enlargement and inlet and outlet error value is relatively significant. In smaller current state, the generated energy is lower, and the electrode size is relatively small, so about before $14.5 \mathrm{~A}$, the error amount changes slightly. When this value is exceeded, the error increases as the energy increases. In smaller current state, as the energy is lower, the discharge is unstable, the electrode wear is too large, the discharge is effective until the energy is $12 \mathrm{~A}$.

(3) Under different voltage conditions, the hole enlargement and inlet and outlet error change significantly, the optimum parameter values shall be found out using the advantages of DOE. The hole enlargement will vary with the inlet and outlet error. Before $55 \mathrm{~V}$ discharge voltage, the electrode consumption is relatively stable (difference is about $0.01 \mathrm{~g}$ ), the consumption will have positive effect in this region. When the voltage is $60 \mathrm{~V}$, the energy increases, the consumption, hole enlargement and inlet and outlet error increase accordingly.

(4) Under different capacitance conditions, the trend of hole enlargement and inlet and outlet error is close to different voltage conditions, because the higher capacitance will generate higher instantaneous voltage. According to the electrode wear, the capacitance has great effect, when the capacitance is 2 , the electrode consumption is lower (difference is about $0.2 \mathrm{~g}$ ). According to robust experiment, the inlet-outlet difference of optimized parameters is improved by
$17.9 \%$ compared with the original parameters, so this experimental model is correct.

\section{Reference:}

[1]Xu, Z.Y., Zhang, Y., Ding, F. et al. An electrochemical discharge drilling method of small deep holes. Int J Adv Manuf Technol 95, 3037-3044 (2018). https://doi.org/10.1007/s00170-017-1355-1

[2]Mao, X., Wang, X., Li, C. et al. Effects of stepped cylindrical electrode in electrical discharge machining of blind holes. Int J Adv Manuf Technol 110, 1457-1469 (2020). https://doi.org/10.1007/s00170-020-05941-3

[3]CFM International company, twin axial flow turbofan engine with high bypass ratio.

[4] GF (AGIE CHARILLES) website.

[5]P. K. Wright and J. G. Chow,1982, Deformation Characteristics of Nickel Alloys During Machining, ASME, Journal of Engineering for Industry, pp.85-93.

[6]M. C. Shaw, A. L. Thurman and H. J. Ahlgren,1966,A Plasticity Problem Involving Plane Strain and Plane Stress Simultane ously Groove Formation in the Machining of High Temper ature Alloys, Trams of ASME,pp.142-146.

[7] KÖNIG. W. , and Zaboklicki. AK,1993,Laser-assisted Hot Machining of Ceramics and Composite Materials , International Conferenceon Machining of Advanced Material Tokyo,pp.455-463.

[8]J. S. Soni and G. Chakraverti, 1994, Machining characteristics of titanium with rotary electro-discharge machining, Wear , pp.51-58

[9]B. H. Yan, F. Y. Huang, H. M. Chow and J. Y. Tsai, 1999, Micro-hole machining of carbide by electric discharge machining, Journal of Material Processing Technology, pp. $139-145$

[10]Huang Jin Hong, 2000, Research on the consumption of small-area electrodes in electric discharge machining for mold carving, National Taiwan University, master's thesis.

[11]Peng Jin Ri, 1998, Research on the characteristics of rapid piercing electrical discharge machining of several difficult-to-machine materials, National Central University, Master's thesis. 
[12]Yeh C. C. , Wu K. L., Lee J. W. and, Yan, B. H., Study on surface characteristics using phosphorous dielectric on wire electrical discharge machining of polycrystalline silicon The International Journal of Advanced Manufacturing Technology, volume 69, pages71-80 (2013)

[13] Zheng Xin Yi, 2010, Research on key technologies of deep micro hole EDM, Dalian University of Technology, $\mathrm{PhD}$ thesis.

[14] Su Jian Jia, 2003, Research on the characteristics of small diameter deep hole EDM, National Taiwan University, Master's thesis.

[15]Kai E., Yosuke M., Yasuki H., Electrical discharge machining of submicron holes using ultrasmall-diameter electrodes, Precision Engineering, Volume 34, Issue 1, January 2010, Pages 139-144

[16] D. HE, T. SHINSHI, X. ZHANG, T. YUZAWA, T. SATO, Improving the Speed of Small Deep Hole Electrical Discharge Machining by Combining Rotation of the Electrode with a Rapid-Response, Journal of Advanced Mechanical Design, Systems, and Manufacturing, 2011 Volume 5 Issue 4 Pages 284-294.

[17]Yih-Fang Chang, Zhi-Hao Chiu, 2004, Electrode wear-compensation of electric discharge scanning process using a robust gap-control, Mechatronics, pp.1121-1139.

[18]Xiao Yuz Uo, 2008, Research on the best assembly parameters of single-axis feed platform positioning accuracy, National Chung Hsing University, Master's thesis.

[19] D. C .Montgomery , Design and Analysis of Experiment, 5th, New York, 2001.

[20] Li Zheng Zhong, 2006, by Montgomery, Experimental Design and Analysis, Sixth Edition, Gao Li Book Co., Ltd.

[21]T. Muthuramalingam, B.Mohan, Performance analysis of iso current pulse generator on machining characteristics in EDM process, Archives of Civil and Mechanical Engineering, Volume 14, Issue 3, May 2014, Pages 383-390.

[22]S. Wilczek, J. Schulze, R. P. Brinkmann, Z. Donkó, J. Trieschmann, and T. Mussenbrock, Electron dynamics in low pressure capacitively coupled radio frequency discharges, Journal of Applied Physics, 127, 181101 (2020); https://doi.org/10.1063/5.0003114.

[23]Huu-Phan Nguyena, Ngoc-Vu Ngob, Quoc-Tuan Nguyena, Optimizing process parameters in edm using low frequency vibration for material removal rate and surface roughness, Journal of King Saud University Engineering Sciences, Available online 15 May 2020.

[24] N. H. Phan, N.V. Duc, P.V. Bong, Application of response surface methodology for evaluating material removal rate in die-sinking EDM roughing using copper electrode, Sci. Technol. Dev. J. Eng. Technol., 1 (2018), pp. 20-27

[25] A.S. Sachin, M.L. Kulkarni

Optimization of machining parameters of WEDM for Nimonic-75 alloy using principal component analysis integrated with Taguchi method J. King Saud Univ. - Eng. Sci., 30 (3) (2018), pp. 250-258

[25] T. Muthuramalingam, B. Mohan, A. Rajadurai \& M. D. Antony Arul Prakash, Experimental Investigation of Iso Energy Pulse Generator on Performance Measures in EDM, Materials and Manufacturing Processes Volume 28, 2013 - Issue 10.

[26]Chmer Electromechanical Industry Co., Ltd., technical report. 


\section{Conflict of interest}

Titled: Using Response Surface Methodology of Deep Hole Electrical Discharge Machining Study of Nickel-Base Alloy Inconel-718

Author: Shao-Hsien Chen, and Kuo-Tai Huang

No.: JAMT-D-21-00451

We declare that we have no financial and personal relationships with other people or organizations that can inappropriately influence our work, there is no professional or other personal interest of any nature or kind in any product, service and/or company that could be construed as influencing the position presented in, or the review of, the manuscript entitled, "Using Response Surface Methodology of Deep Hole Electrical Discharge Machining Study of Nickel-Base Alloy Inconel-718” All authors have declare that: (i) no support, financial or otherwise, has been received from any organization that may have an interest in the submitted work; and (ii) there are no other relationships or activities that could appear to have influenced the submitted work."

\section{Authors Contributions:}

Author ${ }^{1}$ :Shao-Hsien Chen (Conceived and designed the analysis $、$ Contributed data or analysis tools Performed the analysis $、$ Wrote the paper)

Author ${ }^{2}$ :Kuo-Tai Huang (Collected the data C Contributed data or analysis tools - Wrote the paper)

Shao-Hsien Chen Shao-Hien chen

Title: Associate Professor

The Graduate Institute of Precision Manufacturing

National Chin-Yi University of Technology

No.57, Sec. 2, Zhongshan Rd., Taiping Dist., Taichung 41170, Taiwan 